Molecular and Population Genetics Laboratory, Imperial Cancer Research Fund, London

WC2A 3PX, UK $\mathrm{K}$ Woodford-Richens I P M Tomlinson

Cancer Genetics, Institute of Cancer Research, Sutton, Surrey SM2 5NG, UK $S$ Bevan

R S Houlston

Tumour Genetics Group, Nuffield Department of Clinical Medicine, University of Oxford, Wellcome Trust Centre for Human Genetics, Windmill Road, Oxford OX3 7BN, UK

M Churchman B Dowling

Molecular Genetics Laboratory, Churchill Hospital, Oxford OX3 7LJ, UK $D$ Jones

C G Norbury

Department of Clinical Genetics, Guy's Hospital, St Thomas's Street, London

SE1 9RT, UK

S V Hodgson

Polyposis Registry, St Mark's Hospital,

Watford Road, Harrow

HA1 3UJ, UK

D Desai

K Neale

R K S Phillips

Queensland Institute of Medical Research, Royal Brisbane

Hospital, Brisbane, Australia

J Young

B Leggett

MRC Human Genetics Unit, Western General Hospital, Edinburgh EH4 2XU, UK

M Dunlop

Department of Gastroenterology, Tel Aviv Medical Center and Medical School, IL-64239 Tel Aviv, Israel

P Rozen

Human Cancer Genetics Program, Ohio State University Comprehensive Cancer Center, Columbus, OH 43210, USA

C Eng

\title{
Analysis of genetic and phenotypic heterogeneity in juvenile polyposis
}

K Woodford-Richens, S Bevan, M Churchman, B Dowling, D Jones , C G Norbury, S V Hodgson, D Desai, K Neale, R K S Phillips, J Young, B Leggett, M Dunlop, P Rozen, C Eng, D Markie, M A Rodriguez-Bigas, E Sheridan, T Iwama, D Eccles, G T Smith, J C Kim, K M Kim, J R Sampson, G Evans, S Tejpar, W F Bodmer, I P M Tomlinson, R S Houlston

\begin{abstract}
Background-Juvenile polyposis syndrome (JPS) is characterised by gastrointestinal (GI) hamartomatous polyposis and an increased risk of GI malignancy. Juvenile polyps also occur in the Cowden (CS), Bannayan-Ruvalcaba-Riley (BRRS) and Gorlin (GS) syndromes. Diagnosing JPS can be problematic because it relies on exclusion of CS, BRRS, and GS. Germline mutations in the PTCH, PTEN and DPC4 (SMAD4) genes can cause GS, CS/BRRS, and JPS, respectively.

Aims-To examine the contribution of mutations in PTCH, PTEN, and DPC4 (SMAD4) to JPS.

Methods-Forty seven individuals from 15 families and nine apparently sporadic cases with JPS were screened for germline mutations in DPC4, PTEN, and PTCH.

Results-No patient had a mutation in $P T E N$ or PTCH. Five different germline mutations were detected in DPC4; three of these were deletions, one a single base substitution creating a stop codon, and one a missense change. None of these patients had distinguishing clinical features.

Conclusions-Mutations in PTEN and $P T C H$ are unlikely to cause juvenile polyposis in the absence of clinical features indicative of CS, BRRS, or GS. A proportion of JPS patients harbour DPC4 mutations $(21 \%$ in this study) but there remains uncharacterised genetic heterogeneity in JPS.

(Gut 2000;46:656-660)
\end{abstract}

Keywords: juvenile polyposis syndrome; germline mutations

Juvenile polyposis (JPS; MIM 174 900) is a rare autosomal dominant condition characterised by hamartomatous polyps, usually within the colon but occasionally arising in the stomach and small bowel. ${ }^{1}$ These polyps are typified by a predominant stroma, cystic spaces, and an abundant lamina propria lacking smooth muscle, so distinguishing them from Peutz-Jeghers polyps. Unlike solitary juvenile polyps which may affect up to $2 \%$ of children and adolescents and have little or no malignant potential, JPS patients have an increased risk of gastrointestinal malignancy. ${ }^{2}$ JPS may occur in association with arteriovenous malformations (MIM 175 050) but it is not clear if this represents a distinct syndrome.

Juvenile polyps also occur as a manifestation of the dominantly transmitted familial cancer syndromes: Cowden syndrome (CS; MIM 158 350) characterised by multiple hamartomas, macrocephaly, trichilemmomas, and a high risk of benign and malignant neoplasms of the thyroid, breast, uterus and skin; BannayanRuvalcaba-Riley syndrome (Bannayan-Zonana syndrome, BRRS, BZS; MIM 153 480) characterised by mental retardation, macrocephaly, lipomatosis, haemangiomas and genital pigmentation; and Gorlin syndrome (GS; MIM 109 400) characterised by multiple naevoid basal carcinomas, skeletal abnormalities, and odontogenic keratinocytes, macrocephaly, intracranial calcification, and craniofacial abnormalities. Compared with JPS the risk of gastrointestinal malignancy in CS, BRRS, and GS appears to be low. ${ }^{4}$

GS results from germline mutations in the PTCH gene (homologue of Drosophila patched)

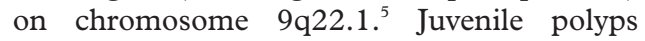
appear to comprise a relatively minor and infrequent component of this disease although few GS patients undergo gastrointestinal screening. Nevertheless, $P$ TCH remains a good candidate for JPS given the possibility that a different spectrum of mutations might cause juvenile polyps without the other features of GS. No study to date has tested PTCH for germline mutations in JPS patients.

The CS gene is PTEN (phosphatase and tensin homologue deleted on chromosome 10 (10q22-q23)), ${ }^{6}$ a ubiquitously expressed dual specificity phosphatase that acts as a tumour suppressor and is mutated in several sporadic tumour types..$^{7-12}$ The inference from patients' clinical features that CS and BRRS might represent allelic forms of the same disease is supported by demonstration of germline mutations in PTEN in some ${ }^{13-15}$ but not all patients with BRRS. ${ }^{16}$ The shared clinical features of CS/BRRS and JPS, coupled with coincident somatic mutation data in juvenile polyps, ${ }^{17}$ raised the possibility that PTEN could cause all of these syndromes. This hypothesis has been

Abbreviations used in this paper: JPS, juvenile polyposis syndrome; CS, Cowden syndrome; BRRS, Bannayan-Ruvalcaba-Riley syndrome; GS, Gorlin syndrome; CSGE, conformation specific gel electrophoresis; SSCP, single strand conformational gel polymorphism. 
Molecular Genetics Laboratory, Pathology Department, Dunedin School of Medicine, Dunedin, New Zealand D Markie

Roswell Park Cancer Institute, Buffalo, New York 14263, USA M A Rodriguez-Bigas

Department of Clinical Genetics, Royal Hospital for Children, St Michael's Hill, Bristol, UK

E Sheridan

Centre for Polyposis and Intestinal Diseases, 1-5-45, Yushima, Bunkyo-Ku, Tokyo 113, Japan T Iwama

Wessex Regional Genetics Service, Southampton SO16 5YA, UK D Eccles

Department of Histopathology, Worcester Royal Infirmary, WR1 3AS, UK

G T Smith

Department of Paediatrics, University of Ulsan College of Medicine, and Asan Institute, Seoul, Korea J C Kim

K M Kim

Institute of Medical Genetics, University of Wales College of Medicine, Cardiff CF4 4XN, UK J R Sampson

Regional Genetic Service, St Mary's Hospital, Manchester M13 0JH, UK G Evans

Centre for Human Genetics, Campus Gasthuisberg, $O$ and N6, B-3000, Leuven, Belgium

S Tejpar

Cancer Immunogenetics Laboratory, ICRF, Institute of Molecular Medicine, Oxford OX3 9DS, UK W F Bodmer

Correspondence to: R Houlston, Haddow Laboratories, Institute of Cancer Research, Sutton, Surrey SM2 5NG, UK. Email: r.houlston@icr.ac.uk 25 November 1999 pursued by a number of workers with differing findings. ${ }^{18-22}$ Some studies found germline PTEN mutations in individuals who had been diagnosed as having JPS but there is doubt that a diagnosis of CS/BRRS had been formally excluded in these patients. We have previously found no PTEN mutations in a relatively large set of JPS patients (including a subset of the cases reported below).

Recently it has been shown that constitutional mutations in DPC4 (deleted in pancreatic carcinoma locus 4 ; also referred to as $S M A D 4$, small mothers against decapentaplegic deleted in pancreatic carcinoma, locus 4) can cause JPS. ${ }^{23}{ }^{24}$ This gene, which codes for a protein involved in transforming growth factor $\beta$ signal transduction, is mutated in a number of gastrointestinal cancers. ${ }^{25}{ }^{26}$ Previous studies have reported DPC4 mutations in 5/9 (56\%) and $1 / 21(5 \%)$ JPS patients (the latter study including a subset of the cases reported below). Other members of the SMAD family are candidates for JPS but no mutations in SMAD 1/2/3/5/6/7 have been found in JPS patients. ${ }^{27}$

Hereditary mixed polyposis syndrome (HMPS, MIM 601228 ) is also characterised by atypical juvenile polyps with mixed features of hamartomas and adenomas. ${ }^{28}$ No gene for this syndrome has been identified but linkage to chromosome $6 \mathrm{q}$ has been reported in one large family. ${ }^{29}$

Hence there is evidence of considerable genetic heterogeneity in JPS. We have studied 56 individuals with a presumptive diagnosis of JPS, comprising 47 cases from 15 JPS families and nine apparently sporadic cases. These patients comprise an exceptionally large set of JPS cases. Our aims were: (i) to describe the clinical features of JPS patients (including features overlapping with CS, BRRS, and GS); (ii) to resolve the debate as to whether or not PTEN mutations account for any cases of JPS; (iii) to test $P T C H$ as a candidate gene for JPS; (iv) to determine the contribution of DPC4 mutations to JPS; (v) to assess the existence of any associations between germline mutations and clinical features; and (vi) to determine the proportion of JPS cases caused by as yet unidentified genes.

\section{Patients and methods}

Patients with JPS were identified from sources in the UK, Australia, Israel, USA, Japan, and Korea. The diagnostic criteria for JPS used in this study were in accordance with the proposal of Ko and colleagues ${ }^{30}$ that affected individuals have either five or more juvenile polyps throughout the gastrointestinal tract or any number of juvenile polyps and a family history of JPS. All affected individuals had more than one typical juvenile polyp as confirmed by histology. The following clinical data were also obtained using a standardised proforma: family history; occurrence of benign and malignant tumours; dysmorphic features; arteriovenous malformations and other cardiovascular anomalies; pigmentation; and other notable clinical features including those of CS, BRRS, and GS. Where possible, material from JPS polyps and other tumours was obtained for histological review and confirmation of diagnosis.

Constitutive DNA from individuals was extracted from EDTA blood samples using a standard sucrose lysis method. Published oligonucleotide and reaction conditions were used to amplify specifically each exon of the DPC4, PTEN, and PTCH genes. ${ }^{24} 31$ The search for germline mutations in DPC4 was performed using conformation specific gel electrophoresis (CSGE). Two independent workers using either CSGE or single strand conformational gel polymorphism (SSCP) undertook screening for mutations in PTEN. A combination of CSGE and SSCP was used to screen the PTCH gene. All samples with band shifts were sequenced in duplicate and in forward and reverse orientations, after reamplification of the appropriate exon from genomic DNA in the polymerase chain reaction, using the ABI Ready Reaction Dye Terminator Cycle Sequencing kit and the 377 Prism sequencer.

\section{Results}

Fifty six patients with JPS were studied; 47 were ascertained from 15 families and nine apparently sporadic patients had no known relatives affected with JPS, although in three cases there was a strong family history of colorectal cancer. Table 1 details the clinical characteristics of all patients. Mean age at presentation of juvenile polyposis was 23 (SD 16) years (range 1-65). All affected individuals from whom histological material was available had juvenile polyps of a typical type.

The extent of polyposis within the gastrointestinal tract varied considerably between families in terms of both the numbers and sites of polyp formation. Some of the families showed marked evidence of intrafamilial differences in disease expression (table 1) even allowing for factors such as patient age and screening by colonoscopy. Furthermore, in a number of patients there was documented evidence of adenomatous intestinal polyposis although none had the atypical juvenile polyps found in HMPS.

The increased risk of gastrointestinal cancer reported in association with JPS was clearly present in our patients. Fifteen (27\%) had developed some type of gastrointestinal cancer by the age of 65 . Of these, six were small bowel carcinomas, two gastric cancers, and seven colorectal cancers. Based on cancer incidence rates in the $\mathrm{UK}^{32}$ this equates to about a 16-fold increased risk of gastrointestinal malignancy in JPS.

None of the patients had prototypical dermatological (e.g. tricholemmomas) or skeletal phenotypic features indicative of CS, BRRS, or GS. There was some overlap between the clinical features of JPS patients and these other syndromes - three patients had macrocephaly for example-but no specific features to suggest misdiagnosis. Furthermore, none of the patients had a past history of thyroid cancer and only one had developed breast cancer. Three patients had hyper- or 
hypothyroidism but no tissue diagnosis suggestive of CS. The increased risk of cancer in these JPS patients appeared to be confined to the gastrointestinal tract in contradistinction to CS and GS. Arteriovenous and other cardiovascular anomalies were present in three patients $(5 \%)$. The reported association between JPS and these anomalies may therefore be genuine.

Table 1 Clinical features of the patients studied

\begin{tabular}{|c|c|c|c|c|c|c|c|c|c|c|c|c|}
\hline \multirow[b]{2}{*}{ Family } & \multirow[b]{2}{*}{$I D$} & \multirow[b]{2}{*}{$A g e^{\star}$} & \multirow[b]{2}{*}{ Sex } & \multicolumn{8}{|l|}{ Phenotype } & \multirow[b]{2}{*}{ Additional information } \\
\hline & & & & Gastrointestinal tract $* \star$ & Skin & Skeletal & CNS & Cardiac & Breast & Thyroid & Other & \\
\hline $\mathrm{W}$ & 3 & 47 & $\mathrm{~F}$ & $\begin{array}{l}\text { Caecal Ca aged } 47 \text {, jejunal JPs and } \\
\text { adenomas, TA }\end{array}$ & & & & & & & & \\
\hline W & 2 & 14 & $\mathrm{~F}$ & $100+J P s$ & & & & & & & & \\
\hline W & 1 & 32 & $\mathrm{~F}$ & Ca colon (transverse) aged 32, & & & & & BBD & Hyper & & \\
\hline SK & 1 & 13 & $\mathrm{~F}$ & $\begin{array}{l}\text { Multiple colonic polyps } \\
\text { (mixed, Ad and JPs) }\end{array}$ & & & & & & & & \\
\hline SRO & 1 & 13 & $\mathrm{~F}$ & Multiple JPs & & & & & & & $\mathrm{P}$ & \\
\hline SS & 1 & 29 & $\mathrm{~F}$ & $(50+) \mathrm{JPs}$ & & & & & & & & $\begin{array}{l}\text { Niece Ca colon (25); } \\
\text { sister Ca pancreas; } \\
\text { father Ca larynx and } \\
\text { stomach }\end{array}$ \\
\hline SV & 1 & 12 & M & Sigmoid and rectal polyps $(50+)$ & & & & & & & & $\begin{array}{l}\text { Father Ca colon aged } \\
48 ; \text { Pat. uncle } \mathrm{Ca} \text { colon } \\
\text { aged } 50\end{array}$ \\
\hline SH & 1 & 1 & M & $\begin{array}{l}\text { Multiple colonic polyps, resection aged } \\
8\end{array}$ & & CLP, PD & & & & & & \\
\hline SC & 1 & 16 & M & Colonic $(30-50)$ & & MC & & & & & & \\
\hline SD & 1 & 15 & M & Jejunal polpys & & & & $\mathrm{CD}$ & & & & \\
\hline SR & 1 & 4 & $\mathrm{~F}$ & Recto-sigmoid and Caecal polyps $(50+)$ & & & & VSD & & & & \\
\hline $\mathrm{AF}$ & 1 & 16 & M & Colonic polyps (4) & & & & & & & & $\begin{array}{l}\text { Father JPs and Ca } \\
\text { colon } \star \star \star\end{array}$ \\
\hline SCA & 1 & 27 & $\mathrm{~F}$ & Multiple sigmoid polyps & & & & & & & & \\
\hline \multirow[t]{3}{*}{3} & 3.5 & 37 & $\mathrm{M}$ & Colonic and gastric polyps & & & & & & & & \\
\hline & 4.2 & 6 & M & $\begin{array}{l}\text { Ileal, jejunal, colonic, and rectal polyps; } \\
\text { Ca ileum; Ca stomach }\end{array}$ & & & & & & & & \\
\hline & 2.3 & 65 & $\mathrm{~F}$ & Colonic and rectal polyps & ML & & & & & & & \\
\hline \multirow[t]{3}{*}{10} & 102 & 41 & $\mathrm{~F}$ & Ca colon & & & & & & & & \\
\hline & 202 & 21 & M & Ileum and colon & & & & & & & & \\
\hline & 201 & 24 & M & Multiple & & & & & & & & \\
\hline \multirow[t]{3}{*}{1} & 204 & 32 & $\mathrm{~F}$ & $\begin{array}{l}\text { Small bowel, colonic and gastric polyps } \\
\text { (JPs and Ad, 20+); Ca ileum aged 49; } \\
\text { intussusception }\end{array}$ & & & & & & & & $\begin{array}{l}\text { Sister, lymphoma aged } \\
42 \text {, Ca breast aged } 54 \text {. }\end{array}$ \\
\hline & 302 & 16 & M & Colonic polyps & & & & & & & & \\
\hline & 301 & 21 & $\mathrm{~F}$ & Colonic polyps (20) & & & & & & & & \\
\hline \multirow[t]{4}{*}{6} & 302 & 23 & M & $\begin{array}{l}\text { Colonic and small intestinal polyps } \\
(50+)\end{array}$ & & MC & & & & & & \\
\hline & 402 & 9 & $\mathrm{~F}$ & Colonic polyps & & & & & & & & \\
\hline & 201 & 55 & $\mathrm{~F}$ & Colonic polyps (3) & & & & & & & & \\
\hline & 401 & 12 & $\mathrm{M}$ & Colonic polyps (2) & & & & & & & & \\
\hline \multirow[t]{2}{*}{11} & 4.4 & 18 & M & Colonic polyps (3) & & & & & & & HT & \\
\hline & 3.5 & 30 & M & Colonic polyps & FK & & & & & & SR & \\
\hline \multirow[t]{3}{*}{8} & 1.2 & 50 & $\mathrm{~F}$ & Ca colon aged 50 & & & & & & & & \\
\hline & 3.1 & 20 & M & Caecal polyps & & & & & & & & \\
\hline & 2.1 & 18 & $\mathrm{~F}$ & Multiple JPS; Ca stomach & & & & & & & & \\
\hline \multirow[t]{3}{*}{9} & 301 & 17 & $\mathrm{M}$ & Colonic polyps & & & & & & & & \\
\hline & 203 & 19 & $\mathrm{~F}$ & JPs and Ad polyps in colon & & & & & & & $\mathrm{BK}$ & \\
\hline & 302 & 4 & M & Colonic polyps & & & & AS and & & & & \\
\hline \multirow[t]{5}{*}{15} & 502 & 14 & M & Multiple colonic polyps & & $\mathrm{CL}$ & & & & & & \\
\hline & 305 & 51 & $\mathrm{~F}$ & $\begin{array}{l}\text { Ca colon (transverse) aged 51, multiple } \\
\text { colonic polyps }\end{array}$ & & & & & & Hypo & & $\begin{array}{l}\text { Brother Ca colon aged } \\
38 \text {, multiple colonic } \\
\text { polyps }\end{array}$ \\
\hline & 306 & 43 & M & Colonic polyps (10) & & & & & & & & \\
\hline & 308 & 61 & M & Caecal Ca aged 61 & & & & & & & & \\
\hline & 405 & 48 & $\mathrm{~F}$ & Multiple colonic polyps & & $\mathrm{CL}$ & & $\mathrm{AR}$ & & Hyper & ovc & \\
\hline 12 & 204 & 8 & M & Multiple colonic polyps; $\mathrm{Ca}$ jejunum & & & SAH & & & & & \\
\hline & 206 & 8 & M & Multiple colonic polyps & & & & & & & & \\
\hline & 201 & 7 & M & Polyposis at autopsy & & & & & & & & \\
\hline & 307 & 4 & $\mathrm{~F}$ & $\begin{array}{l}\text { Florid colonic polyposis; small intestinal } \\
\text { polyps (22); Ca small intestine aged } 27 \text {. }\end{array}$ & & & & & & & OVC & \\
\hline & 304 & 22 & $\mathrm{~F}$ & Caecal and colonic polyps & & & & & & & & \\
\hline & 308 & 17 & M & $\begin{array}{l}\text { Multiple (TA, Ad and JP) in colon and } \\
\text { duodenum; Ca jejunum }\end{array}$ & & MC & & & & & & \\
\hline & 203 & 7 & $M$ & Ca jejunum aged 37 & & & Schiz & & & & & \\
\hline 16 & 102 & 19 & $\mathrm{~F}$ & Ca colon aged 60 & & & & $\mathrm{BBD}$ & & & & \\
\hline & 301 & 13 & $\mathrm{~F}$ & $20+$ polyps & & & & & & & & \\
\hline & 302 & 14 & M & Multiple colonic polyps & & & & & & & & \\
\hline & 201 & 32 & M & Multiple polyps in colon and stomach & & & & & & & & \\
\hline 17 & 202 & NK & M & $>100$ gastric JPs, 8 colorectal JPs & & & & & & & & \\
\hline & 203 & NK & M & Gastric JPs & ML & & & & & & & \\
\hline 20 & 201 & NK & $\mathrm{F}$ & Extensive polyposis, colectomy aged 45 & & & & & & & & \\
\hline & 301 & NK & $\mathrm{F}$ & Colorectal JPs; colectomy aged 21 & & & & & & & ovc & \\
\hline BL & 101 & 39 & M & Colonic polyps $(\mathrm{TA}+\mathrm{Ad})$ & & & & & & & & \\
\hline & 201 & 6 & $\mathrm{~F}$ & $\begin{array}{l}>100 \mathrm{JP} \text {, exocrine pancreatic } \\
\text { insufficiency }\end{array}$ & & & & & & & & $\begin{array}{l}\text { Short stature, } \\
\text { development delay }\end{array}$ \\
\hline
\end{tabular}

*At diagnosis (NK, not known); ${ }^{\star \star}$ number of polyps in parentheses; ${ }^{\star \star \star}$ familial case but only index case analysed.

Ad, adenoma; AR, aortic regurgitation; AS, aortic stenosis; BBD, benign breast disease; BK, bifid kidney; Ca, Cancer; CD, conduction defect; CLP, cleft palate; CL, clinodactylyl; CO, coarctation; FK, excessive freckling; HT, hypertelorism; Hyper, hyperthyroidism; Hypo, hypothyroidism; JPs, juvenile polyps; MC, marcocephaly; ML, multiple lipomas; OVC, ovarian cyst; P, poryphria; PD, polydactylyl; SAH, subarchnoid haemorrhage; Schiz, schizophrenia; SR, Schatski ring; TA, tubular adenoma; VSD, ventricular septal defect. 
Table 2 Description of DPC4 mutations identified in FPS patients

\begin{tabular}{lll}
\hline $\begin{array}{l}\text { Patient/ } \\
\text { family }\end{array}$ & Mutation & Predicted effect \\
\hline SV & $\begin{array}{l}\text { 11bp deletion (GTCCACTGAAG) at } \\
\text { nucleotide 516 (exon 4) }\end{array}$ & $\begin{array}{l}\text { Frameshift creating stop codon at } \\
\text { nucleotide 561 } \\
\text { Arg to Cys }\end{array}$ \\
AF & $\begin{array}{l}\text { CGC to TGC, at nucleotide 1083 } \\
\text { (exon 8) }\end{array}$ & $\begin{array}{l}\text { Frameshift creating stop codon at } \\
\text { nucleotide 1575 } \\
\text { (exp deletion (CC) at nucleotide 1564 }\end{array}$ \\
$\begin{array}{l}\text { 9 bp deletion (AAATGGAGC) at } \\
\text { nucleotide 189 (exon 1) }\end{array}$ & $\begin{array}{l}\text { Deletion of amino acids 64-66 } \\
\text { CGA to TGA at nucleotide 1333 } \\
\text { (exon 10) }\end{array}$ & Substitution creating stop codon \\
BL & & \\
\hline
\end{tabular}

No JPS patient had a germline PTEN mutation. Control samples with known PTEN mutations showed aberrant SSCP bands and previously reported polymorphisms were detected. PTEN mutations are typically found in $80 \%$ of CS and $50 \%$ of BRRS cases which adhere to operational diagnostic criteria established by the International Cowden Consortium..$^{33}$ Also, germline PTCH mutations were not detected in our JPS cases. PTCH mutations are typically detectable in $39 \%$ of GS patients. ${ }^{31}$

Five germline DPC4 mutations were identified (table 2). Three of these were deletions ranging in size from two to 11 base pairs in exons 1,4 , and 11 . One of the mutations was a single base substitution creating a stop codon in exon 10. The fifth mutation was a missense mutation in exon 8. This variant has been reported previously. ${ }^{24}$ Our series therefore confirms that mutations in DPC4 are associated with JPS but the mutations we detected did not involve the trimerisation domain of the $D P C 4$ protein. There were no distinguishing clinicopathological features in those patients harbouring DPC4 mutations.

\section{Discussion}

Several syndromes-JPS, CS, BRRS, GS, and HMPS - include juvenile polyps in their phenotype. These diseases can have subtle manifestations and some of their clinical features are not unique. Hence diagnosis is not straightforward. However, it is important to distinguish between these syndromes as the types of cancer associated with each appear to be quite different. A more reliable and objective means of differentiating syndromes than reliance solely on clinical features is clearly desirable, especially in the case of JPS the diagnosis of which is made in part by exclusion. Determining the molecular basis of each of these syndromes clearly offers the best method of establishing a diagnosis.

Until recently the molecular basis of the hamartomatosis polyposis syndromes was unknown. Early somatic data suggested the existence of a putative locus for JPS at 10q22-24, encompassing PTEN. ${ }^{17}$ This observation led several researchers to examine PTEN as a candidate for JPS. No linkage to $10 \mathrm{q} 22$ or mutation in PTEN was detected in either the JPS families or isolated cases studied by Marsh and colleagues. ${ }^{20}$ However, both Olschwang and colleagues ${ }^{21}$ and Lynch and colleagues ${ }^{18}$ reported germline PTEN mutations in patients with multiple juvenile polyps, suggesting that
PTEN was the cause of some JPS cases. Eng has recently questioned their conclusion. ${ }^{33}$ In the study by Olschwang and colleagues, ${ }^{21}$ the adult male patient (G116) also had a laryngeal carcinoma and a heterogeneous thyroid nodule, which is highly suggestive of CS. Furthermore, although both children in the report (G796 and G710) did not have features indicative of CS or BRRS, they were less than 15 years of age. As the penetrance of CS is only $10 \%$ by this age $^{34}$ it is possible that both children will develop features of CS later in life. Similarly, the affected members of the family reported by Lynch and colleagues ${ }^{18}$ had major clinical features consistent with a diagnosis of CS.

Our mutational analysis of JPS patients is the most comprehensive to date. The findings concur with previous work suggesting that the probability of detecting a constitutive mutation in PTEN is not high if a patient's clinical phenotype does not adhere to the International Cowden Consortium operational diagnostic criteria for $\mathrm{CS}^{33}$ or to the specific clinical features of BRRS.

PTCH is a good candidate for JPS but has not previously been tested for germline mutations in JPS patients. We have excluded this gene as a cause of juvenile polyps outside the setting of GS. Although PTCH mutations may directly lead to gastrointestinal hamartoma formation it remains possible that reports of juvenile polyps in GS result from a chance association or from contiguous deletion of PTCH and at least one other gene.

Recent work has identified germline mutations in the DPC4 (SMAD4) gene on 18q21.1 as a cause of some cases of JPS. ${ }^{23}$ In our study $21 \%$ of JPS could be ascribed to germline mutations in DPC4 (five of 24; comprising 15 families and nine sporadic cases tested). This provides further support for the role of mutations in this gene as a cause of JPS. Failure to detect mutations in DPC4 in the other patients is unlikely to reflect problems in the screening method alone: it is possible that some mutations may be in the UTRs, introns, or promoter region of the gene but we have screened all exons and splice sites and have found that CSGE can detect all small insertions, deletions, and $90 \%$ of single base substitutions under such conditions.

$D P C 4 / S M A D 4$ is a pivitol component of the transforming growth factor $\beta$ signal transduction pathway. ${ }^{35}$ Through hetero-oligomer formation by interaction with SMAD1 (and possibly 5) and $S M A D 2$ (and possibly 3), $S M A D 4$ mediates apoptotic and growth inhibition responses. Hamartoma formation in JPS presumably results from disruption of the transforming growth factor $\beta$ signal transduction pathway. ${ }^{35}$ In our study mutations in SMAD4 were detected in exons $1,4,8,10$, and 11. Pathogenic mutations previously reported were in exons 5,8 , and $9 .{ }^{23} \mathrm{~A}$ wide range of mutations can clearly affect cellular responses to transforming growth factor $\beta$ leading to hamartoma formation. Whether specific genotype-phenotype relationships exist await further studies. 
We conclude that the clinical features of Cowden syndrome, Bannayan-RileyRuvalcaba syndrome, and Gorlin syndrome can be used to distinguish patients who are likely to carry germline mutations in PTEN and PTCH and who do not, therefore, have a diagnosis of JPS. The rare syndrome HMPS can probably be distinguished from JPS on histological grounds, and there is no evidence for linkage of JPS to the HMPS locus (although this cannot be confirmed until the HMPS gene is identified). Combining our findings and those reported by Howe and colleagues ${ }^{23}$ suggests that up to $40 \%$ of JPS cases might be caused by germline mutations in DPC4 although these patients cannot be distinguished from the majority of JPS patients who harbour germline mutations in uncharacterised genes. Current evidence does not suggest any common mode of action of PTEN, PTCH, and DPC4. Therefore, there are few clues as to the nature of the uncharacterised genes for JPS as it appears that several different cellular defects are associated with hamartomatous juvenile polyps of identical appearance.

We thank the patients that took part in this study. Part of this work was supported by BREAKTHROUGH Breast Cancer. KW-R is supported by the EEC, SB is in receipt of a Fellowship from the Coeliac Society, MC is supported by the CRC, and BD by the MRC.

1 Jass JR, Williams CB, Bussey HJ, et al. Juvenile polyposis-a precancerous condition. Histopathology 1988;13:619-30.

2 Giardiello FM, Hamilton SR, Kern SE, et al. Colorecta neoplasia in juvenile polyposis or juvenile polyps. Arch Dis Child 1991;66:971-5.

3 Howe JR, Mitros FA, Summers RW. The risk of gastrointestinal carcinoma in familial juvenile polyposis. Ann Surg Oncol 1998;5:751-6.

4 Murday V, Slack J. Inherited disorders associated with colorectal cancer. Cancer Surv 1989;8:139-57.

5 Hahn H, Wicking C, Zaphiropoulous PG, et al. Mutations of the human homolog of Drosophila patched in the nevoid basal cell carcinoma syndrome Cell 1996;85:841-51.

6 Liaw D, Marsh DJ, Li J, et al. Germline mutations of the Liaw D, Marsh DJ, Li J, et al. Germline mutations of the
PTEN gene in Cowden disease, an inherited breast and PTEN gene in Cowden disease, an inherited breast
thyroid cancer syndrome. Nat Genet 1997;16:64-7.

7 thyroid, cancer syndrome. Nat Genet 1997;16:64-7. the putative tumor suppressor gene PTEN/MMAC1 in primary breast carcinomas. Cancer Res 1997;57:3657-9.

8 Guldberg P, thor-Straten P, Birck A, et al. Disruption of the MMAC1/PTEN gene by deletion or mutation is a frequen event in malignant melanoma. Cancer Res 1997;57:3660-3.

9 Tashiro H, Blazes MS, Wu R, et al. Mutations in PTEN are frequent in endometrial carcinoma but rare in other common gynecological malignancies. Cancer Res 1997;57: 3935-40

10 Rasheed BK, Stenzel TT, McLendon RE, et al. PTEN gene mutations are seen in high-grade but not in low-grade gliomas. Cancer Res 1997:57:4187-90.

11 Dahia PL, Marsh DJ, Zheng Z, et al. Somatic deletions and mutations in the Cowden disease gene, PTEN, in sporadic mutations in the Cowden disease gene, PTEN,

12 Steck PA, Pershouse MA, Jasser SA, et al. Identification of a candidate tumour suppressor gene, MMAC1, at chromosome $10 \mathrm{q} 23.3$ that is mutated in multiple advanced cancers. Nat Genet 1997;15:356-62.
13 Marsh DJ, Dahia PLM, Zheng Z, et al. Germline mutations in PTEN are present in Bannayan-Zonana syndrome. Nat Genet 1997; 16:333-4.

14 Arch EM, Goodman BK, Van Wesep RA, et al. Deletion of PTEN in a patient with Bannayan-Riley-Ruvalcaba syndrome suggests allelism with Cowden disease. Am $\mathcal{F}$ Med Genet 1997;71:489-93.

15 Marsh DJ, Coulon V, Lunetta KL, et al. Mutation spectrum and genotype-phenotype analyses in Cowden disease and Bannayan-Zonana syndrome, 2 hamartoma syndromes with germline PTEN mutation. Hum Mol Genet 1998;7: with germ.

16 Carethers JM, Furnari FB, Zigman AF, et al. Absence of PTEN/MMAC1 germ-line mutations in sporadic Bannayan-Riley-Ruvalcaba syndrome. Cancer Res 1998;58: 2724-6.

17 Jacoby RF, Schlack S, Cole CE, et al. A juvenile polyposis tumor suppressor locus at $10 \mathrm{q} 22$ is deleted from nonepithelial cells in the lamina propria. Gastroenterology 1997; 112:1398-403.

18 Lynch ED, Ostermeyer EA, Lee MK, et al. Inherited mutations in PTEN that are associated with breast cancer, Cowden syndrome, and juvenile polyposis. Am f Hum Genet 1997;61:1254-60.

19 Howe JR, Ringold JC, Summers RW, et al. A gene for familial juvenile polyposis maps to chromosome 18q21.1. Am f Hum Genet 1998;62:1129-36.

20 Marsh DJ, Roth S, Lunetta KL, et al. Exclusion of PTEN and $10 \mathrm{q} 2224$ as the susceptibility locus for juvenile polyposis syndrome (JPS). Cancer Res 1997;57:5017-21.

21 Olschwang S, Serova-Sinilnikova OM, Lenoir GM, et al. PTEN germline mutations in juvenile polyposis coli. Nat Genet 1998;18:12-14.

22 Tsuchiya KD, Wiesner G, Cassidy SB, et al. Deletion 10q23.2-10q23.33 in a patient with gastrointestinal juvenile polyposis and other features of a Cowden-like syndrome. Genes Chromosomes Cancer 1998;21:113-18.

23 Howe JR, Roth S, Summers RW, et al. Mutations in the Smad4/DPC4 gene in juvenile polyposis. Science 1998;280: $1086-8$

24 Houlston RS, Bevan S, Williams A, et al. Mutations in DPC4 (SMAD4) cause juvenile polyposis syndrome, but only account for a minority of cases. Hum Mol Genet 1998; 7:1907-12.

25 Schutte M, Hruban RH, Hedrick L, et al. DPC4 gene in various tumor types. Cancer Res 1996;56:2527-30.

26 Hahn SA, Bartsch D, Schroers A, et al. Mutations of the $\mathrm{DPC} 4 / \mathrm{Smad} 4$ gene in biliary tract carcinoma. Cancer Res 1998;58:1124-6.

27 Bevan, S, Woodford-Richens K, Rozen P, et al. Screening SMAD1, SMAD2, SMAD3 and SMAD5 for germline mutations in juvenile polyposis syndrome. Gut 1999;45: 406-8.

28 Whitelaw SC, Murday VA, Tomlinson IP, et al. Clinical and molecular features of the hereditary mixed polyposis syndrome. Gastroenterology 1997;112:327-34.

29 Thomas HJ, Whitelaw SC, Cottrell SE, et al. Genetic mapping of hereditary mixed polyposis syndrome to chromosome 6q. Am f Hum Genet 1996;58:770-6.

30 Ko FY, Wu TC, Hwang B. Intestinal polyps in children and adolescents-a review of 103 cases. Chung Hиа Мin Кио Hsiao Erh Ko I Hsueh Hui Tsa Chih 1995;36:197-202.

31 Wicking C, Shanley S, Smyth I, et al. Most germ-line mutations in the nevoid basal cell carcinoma syndrome lead to a premature termination of the PATCHED protein, and no genotype-phenotype correlations are evident. Am 7 Hum Genet 1997;60:21-6.

32 Cancer Registrations in England and Wales 1986. Office of National Statistics. London: HMSO, 1986.

33 Eng C, Ji HL. Molecular classification of the inherited hamartoma polyposis syndromes: Clearing the muddied waters. Am f Hum Genet 1998;62:1020-2.

34 Nelen MR, Padberg GW, Peeters EA, et al. Localization of the gene for Cowden disease to 10q22-23. Nat Genet 1996; 13:114-16.

35 Heldin $\mathrm{CH}$, Miyazono K, ten Dijke P. TGF-beta signalling from cell membrane to nucleus through SMAD proteins. Nature 1997;390:465-71. 